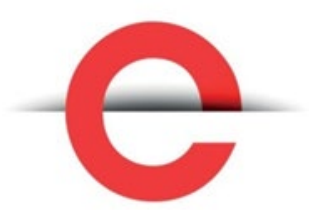

U T S

e P R E S S
Cosmopolitan

Civil Societies:

an

Interdisciplinary

Journal

Vol. 11 , No. 2

2019

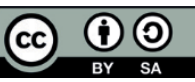

(C) 2019 by the author(s). This is an Open Access article distributed under the terms of the Creative Commons Attribution 4.0 International (CC BY 4.0) License (https://

creativecommons.org/licenses/by/ $4.0 /$ ), allowing third parties to copy and redistribute the material in any medium or format and to remix, transform, and build upon the material for any purpose, even commercially, provided the original work is properly cited and states its license.

Citation: Williams, M. \& Allan, J. 2019. Reducing smoking in Australia: how to include Aboriginal and Torres Strait Islander people. Cosmopolitan Civil Societies: an

Interdisciplinary

Journal, 11:2, 37-54.

https://doi.org/10.5130/

ccs.v11.i2 .6642

ISSN 1837-5391 | Published by UTS ePRESS | https://mcs. epress.lib.uts.edu.au
REFEREED PAPER

\section{Reducing smoking in Australia: how to include Aboriginal and Torres Strait Islander people}

\section{Martin Williams}

University of Technology Sydney, Sydney, Australia

John Allan

University of Queensland, Brisbane, Australia

Corresponding author: Martin Williams, Faculty of Arts and Social Sciences, University of Technology Sydney, 15 Broadway, Ultimo NSW 2007, Australia. Martin.Williams@uts.edu.au

John Allan, Faculty of Medicine, University of Queensland, St Lucia, Queensland 4072 Australia. j.allan3@uq.edu.au

DOI: http://dx.doi.org/10.5130/ccs.v11.i2.6642

Article History: Received 24/06/2019; Revised23/10/2019; Accepted 30/10/2019;

Published 27/11/2019.

\begin{abstract}
Australia has succeeded in lowering the overall prevalence of tobacco smoking in the last four decades and has enjoyed a worldwide reputation for innovative policy. However, this success has not extended to Indigenous Australians. Using a narrative review and critique of literature from government, public health, health promotion, marketing and communication on smoking cessation in Australia, we first consider the history of government anti-smoking measures including legislation and communication initiatives including advertising and sponsorship bans, health warnings and 'no smoking' rules affecting anti-smoking norms, culminating in the banning of branding and the advent of tobacco plain packaging. We also review the effects of excise increases and smoking cessation aids such as quit lines and nicotine replacement therapy. For each type of intervention, both population-wide and those specifically directed at Indigenous people, we consider the probable reasons for the failure to reach Aboriginal and Torres Strait Islander people or alter their smoking patterns, and make suggestions for improvements in interventions and their evaluation. We conclude that the history of antismoking initiatives in Australia suggests that community-based health initiatives are likely to be more effective in addressing Indigenous people and helping smokers to quit.
\end{abstract}

\section{Keywords}

Aboriginal and Torres Strait Islanders, smoking behaviour, health promotion, community based intervention 


\section{Introduction}

With a weight of evidence about the dangers of smoking, and the costs to health systems, the Australian government has prosecuted its case against smoking arguably as strongly as any nation. Anti-smoking measures enacted since the 1970s have included mass media quit campaigns, advertising bans, price increases via taxation, and restrictions around smoking in public spaces, and together have achieved dramatic reductions in the prevalence of smoking. In 2008 all governments in Australia - state, territory and federal - signed a national healthcare agreement (Steering Committee 2009) re-ratified in 2012. These initiatives were expected to reduce adult smoking prevalence to $10 \%$ by 2018 , while cutting the proportion of daily smokers among Aboriginal and Torres Strait Islander people by $50 \%$. However, national anti-smoking measures have had less impact on Aboriginal and Torres Strait Islander people, and specifically aimed programs have been less effective and the results of different interventions less easy to measure. Smoking prevalence among Indigenous people remains alarmingly high, recorded at 39\% in 2014-15 (ABS 2016). Indigenous people aged 15 or over are 2.6 times as likely to smoke as other Australians (ABS 2014; AHMAC 2015) and Indigenous women are four times as likely to smoke during pregnancy as other women (Myers \& Vickers 2015).

Australia's Indigenous population may be among the most disadvantaged indigenous populations in the world (Hill, Barker \& Vos 2007), and socio-economic disadvantage is in itself a predictor of higher smoking rates (Cancer Council Victoria 2013). Additionally, smoking patterns are also likely to reflect cultural aspects particular to this population, including the traditional customs of sharing and kinship bonding (Ivers 2001). Smokers from disadvantaged groups also tend to have higher levels of dependency on nicotine, smoke more cigarettes each day and smoke for more years than the general population (Cancer Council Victoria 2013). Thus, the health consequences are profound. For Aboriginal and Torres Strait Islander people, tobacco smoking is the most preventable cause of ill health and early death. Smoking is responsible for around one in five deaths and for a third of cancer and cardiovascular disease incidence (Vos et al. 2007).

Comprehensive tobacco advertising prohibition in 1994 initiated a slide in smoking from over $24 \%$ of the population to approximately $20 \%$ in 2000 (see Figure 1) (National Preventative Health Taskforce 2008). Subsequent bans on smoking in dining areas, followed by graphic health warnings on packets, hastened the decline to about $15 \%$. After a $25 \%$ increase in excise on cigarettes in 2009 the rate fell to just over 13\% in 2012. Although it is difficult to attribute the effects to individual measures, since 2005 the combined impact of multiple excise increases, the removal of branding from packaging and point-of-sale restrictions together led to dramatic decreases in rates of smoking to just under $13 \%$ in 2014, the lowest smoking prevalence ever recorded in Australia, and just over 13\% in 2017-18 (Greenhalgh, Bayly \& Winstanley 2019). 


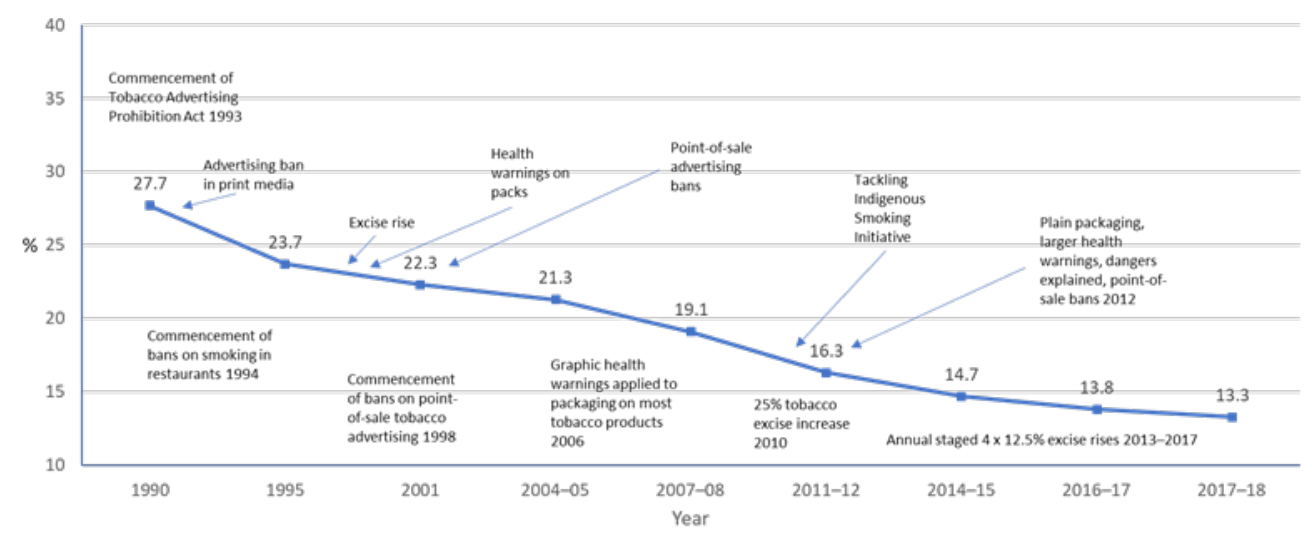

Figure 1: Prevalence of daily smoking for Australians 14 years or older and key tobacco control measures implemented in Australia since 1990 (age-standardised to the 2001 Australian population).

(Source: Adapted from ABS 2015 and 2019.)

However, these national figures mask the unequal impact of anti-smoking measures on Aboriginal communities. Although efforts have been made for many years to reduce Indigenous tobacco use, the delivery of tobacco action programs is marked by limited resources and a lack of coordination (CEITC 2008; Ivers 2011). The Tackling Indigenous Smoking Initiative, announced in 2008, represented a significant commitment to Indigenous tobacco action, but funding was cut in 2014 by $\$ 130$ million over five years, which will lead to Aboriginal deaths.

This paper begins from the premise that in a country which promotes policies of social inclusion, this inclusiveness should be observable in all aspects of life. The marginalisation of any group is a cause for concern, and the further marginalisation of Indigenous people because of the burdens of poor health resulting from smoking is a matter of national significance. We review the literature on smoking cessation from government, public health, and health promotion, through the lens a health professional and a marketing and communications expert, rather than indigenous or Torres Strait Islander people. The paper asks why policies and interventions that have been successful in the Australian population at large have not been successful among Indigenous people, and what approaches, if any, might go some way towards redressing the balance.

\section{Measures adopted in the population at large to reduce smoking}

Advertising and sponsorship bans

Mandatory health warnings for radio and television cigarette advertisements were introduced in 1972, and health warnings appeared on cigarette packs in 1973. In September 1976 tobacco and cigarette advertisements on television and radio were banned. From December 1989 locally produced print media advertising was banned. The Tobacco Advertising Prohibition Act 1992 prohibited almost all forms of tobacco advertising, including sponsorship of sporting and cultural events, by 2007.

'No smoking' rules affecting anti-smoking norms

Anti-smoking norms, especially in the workplace, have a profound effect on the frequency of consumption as well as the uptake of smoking. Smoking bans originated from occupational 
health and safety concerns about passive smoking, leading to progressive restrictions, and spread beyond government and corporations to hospitality venues and public places (Chapman et al. 1999; Walsh, Tzelepis \& McKenzie 2002; Borland, Winstanley \& Reading 2009). Combined with the growing evidence about the health effects and social costs of smoking, these restrictions contributed to a growing anti-smoking sentiment among the population at large. Bans were then extended to sporting and outdoor venues and places where children could be influenced, for example by Queensland's Tobacco and Other Smoking Products Act 1998. However, those who were not working or who were spending their time in unregulated environments were less affected by these changes.

\section{Point-of-sale advertising bans}

Mounting research evidence on the effects of point-of-sale promotion resulted in banning of display of smoking products at point of sale altogether. From 31 December 2010 all retailers were required to store smoking products in special lockers, out of consumers' sight. The effects were significant as Figure 1 shows. However, there is little evidence that point-of-sale policies had an impact among Indigenous people, possibly due to the less stringent application of laws governing display among some communities (Upson 2015).

\section{Total bans on cigarette pack branding}

The 2012 government policy known as 'plain packaging', the most radical legislation anywhere in the world, prohibited the use of tobacco brand logos, colours, imagery or promotional text on cigarette packaging. Further off-putting additions included graphic images of the effects of smoking, information about the chemicals in cigarettes, and Australia's annual smoking-related death rates (Australian Government Department of Health 2019). Treasury data posted on the Health Department's website showed dramatic results. Sales slid and the proportion of the population smoking daily fell still further. However, similar results were not evident within marginalised groups.

\section{Anti-smoking mass media advertising campaign effects}

Substantial international scientific evidence demonstrates that government anti-smoking mass media campaigns have helped smokers quit and prevented children from smoking. National advertising campaigns, taxation and smoke-free legislation have together been successful in the general Australian community. However, there is little evidence for the effectiveness of mass media campaigns in reducing smoking rates among Indigenous Australians (Power, Grealy \& Rintoul 2009; Ivers 2011, 2014). The Tobacco Project in the Northern Territory demonstrated no significant reduction in tobacco use across all communities, with substantial variation between communities (Thomas, Johnston \& Fitz 2010).

Mass media anti-smoking campaigns generally address behaviours in large audiences. However, where audiences lack the resources to change, or where the campaigns do not contain the triggers relevant to the social context of audiences, people may be less disposed to respond. Thus writers have advocated for more attention to Indigenous groups, for example by employing Indigenous health workers to work directly with families (DiGiacomo et al. 2011). 
In 2011, Indigenous leader Professor Tom Calma, the Australian federal government's national coordinator charged with tackling Indigenous smoking, argued that mainstream campaigns were not getting through:

What people want is something that they can relate to and so this [the Indigenous Tobacco Control project] is an attempt to be able to do that. A punitive-type message is not going to help. What we need to do is educate people so that they understand the relationship between smoking and poor health and disease and death (Calma 2011).

He argued that any future campaigns should help Aboriginal and Torres Strait Islander people learn more about the support that is available to help all Australians quit smoking. Research evidence of anti-smoking quit campaigns up to 2015 points to more frequent recall of warning labels, news stories and advertising commonly associated with worry about health and wanting to quit. However, frequent advertising recall was more association with believing that society disapproves of smoking, but less impact on quitting (Nicholson et al., 2015). Although the subsequent anti-smoking 2015 National Tobacco Campaign performed well amongst the majority of the population on most advertising awareness measures, no significant reduction in cessation among Aboriginal people was recorded (Myers \& Vickers 2015).

Researchers concluded there was little evidence that mass media campaigns were effective in reducing smoking rates among Indigenous Australians (Ivers 2011, 2014; Minichiello et al. 2016), which may be due to lack of consistent messaging, difficulty in addressing remote communities, language barriers and so on. A number of campaigns using alternative media, such as apps, DVDs and Facebook ('Quit for you, quit for two', 'Blow away the smokes' and 'Sticking it up the smokes') advocated in the Closing the Gap policy have been initiated in Aboriginal and Torres Strait Islander communities since its declaration in 2009.

However, relatively little attention has been given to the way anti-tobacco messages are communicated to Aboriginal and Torres Strait Islander peoples (Gould et al. 2013). For mass media, achievement of sufficient population exposure is vital, especially among disadvantaged adult smokers, as television remains the primary channel of access to them (Wakefield, Loken \& Hornik 2010). However, the use of inappropriate creative content that may not resonate with the highly addicted is a factor that may explain why Quit advertising has had less effect in Aboriginal smokers (Gould et al. 2016). While evidence from the Talking About The Smokes project 2014 also supports the importance of using targeted advertising, (Thomas et al. 2015) and though the success of social media strategies in health promotion among Indigenous people is scant (Briggs, Lindorff \& Ivers 2003; Brusse 2014), recent evidence of social media use, at least among young Indigenous people, is encouraging: Indigenous young people expressed that they are more drawn to multimedia, video, social networking, animation, music and mobile phones than traditional anti-smoking marketing campaigns. These multimedia forms are more widely accessible because they minimize language and literacy barriers (Wright et al. 2019). 


\section{Pricing effects on smoking cessation}

While excise had been increasing since the $1960 \mathrm{~s}$, the excise on large packets of 25 cigarettes increased substantially after tax reforms were adopted in 1999. Taxes increased again substantially in the following years (see Figure 1). By 2017 government excise had grown to approximately $69 \%$ of the retail price. In 2020 Australians will pay A $\$ 40$ for a packet of 40 cigarettes. This means that it will cost over A $\$ 7000$ a year for someone smoking 20 cigarettes a day.

Economists and others have concluded that virtually all the reduction in tobacco consumption in Australia between 1962-63 and 1995-96 could be attributed to increases in price, resulting mainly from increases in tax levels (Bardsley \& Olekalns 1999; Wakefield et al. 2008). However, Wakefield et al. found that price increases from excise rises had less impact on reduction of consumption in lower income groups. Price rises can cause financial hardship in households where smokers do not quit (Hoek \& Smith 2016), and tax increases can stimulate tobacco company arguments about regressive effects and encourage illicit trade (Hirono \& Smith 2010). A UK-based analysis of tobacco industry submissions to government against excise hikes, found tobacco companies employed the concept of health inequalities to criticise cessation services and tax increases for not addressing underlying causes of disadvantage (Clifford, Hill \& Collin 2014). Further, there is evidence that tobacco companies implement variable cigarette pricing in poorer communities, making cigarettes cheaper (Dalglish et al. 2013), than the then retail equivalent cost of approx. 75 cents Australian on average per cigarette.

Thomas et al. (2013) made an assessment of the impact of a $25 \%$ tax rise on tobacco sales in Aboriginal communities in remote Australia and explored local perceptions about tobacco tax rises and their impact. The study found no significant reduction in total tobacco sold in a store in the seven months after the price increase, compared with the seven months before the price increase, confirming the lack of pricing effects in the researched community. At the same time, cigarette price hikes have had compounding negative effects, for example increased demand for sharing cigarettes, together with increased reliance on those with more money to purchase cigarettes for other smokers (Thomas et al. 2013).

In conclusion, policies to reduce smoking in the population at large have different effects on Indigenous people, among whom price rises may fail to be a disincentive but result in undesirable knock-on effects (Bryant et al. 2011b).

\section{Quit lines and their success}

Several large studies all concluded that telephone quit lines, together with counselling, increase quit rates (Abrams et al. 2010; Stead et al. 2013). The cost effectiveness of telephone counselling has usually been associated with nicotine patches in the US as well as in Australia (Miller, Wakefield \& Roberts 2003), while at least half the nicotine replacement therapy programs aimed at Aboriginal and Torres Strait Islander communities have focused on smoke-free pregnancy (Gould et al. 2014). However, randomised trials of the relative effectiveness and cost effectiveness of different protocols are limited (Bryant et al. 2011a). 
In Australia, most quit lines employ some Aboriginal counsellors, and when respondents identify as Indigenous, same-sex and culturally appropriate counsellors are available (Gould, Bittoun \& Clarke 2015). The National Tobacco Strategy, the Closing the Gap strategies and the National Aboriginal and Torres Strait Islander Health Plan all recommend comprehensive holistic, long-term approaches (Cancer Council Victoria 2013; Holland 2018), involving full participation of Aboriginal and Torres Strait Islander peoples and their representative bodies in all aspects of addressing their health needs, including those communicated by radio, television and social media, through mobile phones. Although several sources of support also involve new media, not all smartphones operate in remote areas, and users may have trouble with recharging or affording prepay in order to make use of telephone counselling.

\section{Nicotine replacement therapy}

Systematic reviews have shown nicotine replacement therapy to be effective in increasing cessation rates. Replacement therapy may work well in Indigenous populations, particularly for pregnant women, who can receive prescribed patches free, but even these programs are not without problems that affect compliance, such as the time taken for supplies to arrive in remote areas, individuals running out of patches because they share with other family members, and the cost to those who are not eligible for subsidies (Gould et al. 2014). Aboriginal respondents perceived nicotine replacement therapy as expensive and an ineffective substitute for smoking (Bryant et al. 2011b). However, nicotine replacement therapy supported through programs is a preferred option voiced by these Indigenous communities and should be a focus of long-term, multifaceted and high-intensity quit programs (Carson et al. 2014). Based on concerns raised by health staff and community members, the acceptability of some unmodified activities by health workers around their personal propensity to smoke, as well as organisational barriers within the health system may be contributing to the reduced effectiveness of tobacco control. In this setting interventions to support government nicotine replacement initiatives appear to stand a better chance of success when combined with more complete advice, including counselling (Johnson \& Thomas 2010) that is culturally appropriate (Martin et al. 2019).

\section{Tobacco interventions in Indigenous communities}

Since Ivers's original 2003 review of tobacco interventions in Indigenous communities in Australia and New Zealand found mixed responses to various trials, she has continually stressed the need for anti-smoking programs to be evaluated comprehensively (Ivers et al. 2006). Hudson's 2016 research at the Centre for Independent Studies in Sydney, Australia noted a lack of evaluation of Indigenous programs in general as a significant problem: of the 1082 Indigenous health, cultural community and early child hood programs identified, only $88(8 \%)$ had been evaluated, while of the 490 programs delivered by Aboriginal organisations, only 20 were evaluated (4\%) (Hudson 2016). In fact, critical evaluations of the various programs undertaken in Aboriginal and Torres Strait Islander communities are sparse and have been limited by small samples and problems of research design with relatively few examples of programs with publicly available outcomes or impact evaluations (Muir \& Dean 2017). 
Little research considers the appropriateness and transferability of initiatives elsewhere to Aboriginal and Torres Strait Islander contexts (Van der Sterren et al. 2016), while there is a need for Indigenous-specific research regarding: the impact of pricing measures;

interventions to reduce tobacco use among adolescents and pregnant women; the effects of the introduction of smoking bans in prisons; and linguistically diverse Indigenous people. There is also a need for Indigenous-specific evidence regarding interventions using social media and mobile applications, electronic cigarettes, and how to protect communities from industry interference (Chamberlain et al. 2017). Robertson et al.'s 2015 systematic review of trends in Indigenous Australian tobacco research from 2004 to 2013 found that, despite a surge in research output in 2008 relating to Indigenous tobacco control, there were still few intervention studies available to guide future efforts. These authors strongly advise rigorous outcome evaluations, particularly of secondary prevention programs and comprehensive community-wide programs, be they delivered by Aboriginal organisations or by government departments. Demaio, Drysdale and de Courten (2012) recommend culturally appropriate health promotion, which strives for understanding, empowerment and respect of communities. According to Gould et al. (2014) and Tane, Hefler and Thomas (2018), clinician involvement is essential, with more thorough education for medical professionals, including specialists, in the cultural mores of these communities required.

Before members of socially excluded groups are able to demand substantive changes in unequal social relations that undermine their health, they need to see themselves as active agents capable of acting to improve their lives (World Health Organisation Report 2010, p.8.) Campbell and Scott (2011) discuss factors that undermine assumptions of individual agency that include unconscious factors, socially constructed peer norms, and power inequalities arising out of social relations, including gender and poverty, where disadvantaged people have experienced far more insecurity, uncertainty and stressful events in their life course, that affects social inequalities in health. Further, there is a growing recognition of the limitations of traditional health promotion in favour of community strengthening. Thus, health campaigns should aim to facilitate types of social participation designed to empower people to resist the impacts of unhealthy social influences (Closing the Gap report, modified 2019), where previously health campaigns and communication have generally overlooked the benefits of participatory forms of communication that are commonplace in marketing goods and services.

Despite these negatives there is hope. A recent review concluded that more effective multifaceted interventions which incorporate Indigenous leadership, partnership, engagement and cultural tailoring are necessary to reduce the burden of tobacco-related disease among Indigenous peoples (Chamberlain et al. 2017), in Australia. However, specific intervention strategies, principles and priorities have tended to be more related to process, while assessment of the outcomes of the interventions have been less well recorded.

A community-based approach does not rule out one-to-one interventions in healthcare (O'Brien et al. 2010). Though Marley et al. (2014) found no significant benefit from a multidimensional smoking cessation intervention, Be Our Ally Beat Smoking (BOABS), the meta- 
analysis of it and an earlier study of pregnant women (Eades et al. 2012) has shown that in a in a primary healthcare setting in encouraging smoking cessation one-on-one intensive intervention was more effective than usual care. Importantly, when delivered by, and provided to Aboriginal and Torres Strait Islander people, such practices can be equally successful in remote areas. However, these programs have to be seen in the light of controlled trials, thus the effectiveness of programs based on close personal support to quit smoking in a real world setting, require to be implemented. As a consequence of their findings, O'Brien et al. (2010) posed the questions: Do experimental interventions work in practice? Are they cost-effective and sustainable? What are the enablers and barriers to the integration of such programs into primary health care for Aboriginal and Torres Strait Islander peoples?

In summary, then, evidence on how to design services to attract Aboriginal and Torres Strait Islander people, whether by media, direct intervention or use of specific cessation tools, is scant. The question therefore remains: What interventions might provide possible solutions for Indigenous people in particular?

\section{Recommendations}

Hill et al. (2007) advocated attention to the way anti-tobacco messages are being developed amongst Aboriginal and Torres Strait Islander peoples, particularly in the absence of any consistency of approach. The report Next steps for Aboriginal health research lays down methodologies of approach, noting that some mainstream services were unresponsive to feedback from Aboriginal people and participants felt that 'no one was listening' (King \& Brown 2015, p. 27). While communication within the public service hierarchy extends to acknowledgment of cultural differences that perpetuates the power of 'the dominant culture' (Downing \& Kowal 2011), Fredericks (2006) argues that training in any intervention must include anti-racism strategies where support for those involved allows them 'to take action within themselves, their work environment, the system [...] and within the broader society' (p. 95). Particular reference is made to the language surrounding some of these programs, which is offensive to Aboriginal people, such as 'Closing the Gap': some Aboriginal commentators have exclaimed, 'What gap?' (Mick Gooda, NSW Office of Aboriginal Affairs Research Agenda seminar, 1 March 2018, University of Technology Sydney Business School, Sydney).

Thus, the risk of propagating the discourse that casts Aboriginal people as problematic, and reinforces stereotypes of dysfunction (Raven et al. 2016), must be addressed by policymakers. Further research is warranted to investigate messaging that has resonance within marginalised Aboriginal populations where language and literacy have so far posed barriers to communication, and thus to knowledge and understanding of quit processes in particular. So, any health or public service communication or evaluation report should acknowledge particular contexts, the community and the specific protocols and relationships that need to be developed to maximise trust and foster genuine partnerships, before programs stand a chance of success (Raven et al. 2016). 
In Aboriginal and Torres Strait Islander communities, the barriers and obstacles to quitting smoking involve psychological, social and cultural factors, including sharing habits (Bryant et al. 2011; Gould et al. 2013). Thus, researchers advise adoption of a more 'bottom-up' process (Gould et al. 2014; Ivers 2014). Such an approach in healthcare mirrors the best practice in customer relationship management (Buttle \& Maklan 2015), where a targeted, comprehensive customer-centric (as opposed to organisation-centric) approach has been found successful. While some recommend mass media campaigns (Gould et al. 2013), the weight of research tends to favour quit campaigns focused on face-to-face contact (Carson et al. 2014; Minichiello et al. 2016). In both approaches the campaigns must be culturally targeted. In these circumstances one-to-one contact may be dependent on mobile phone applications (Johnston et al. 2013) and text messaging with appropriate response devices, in a communication mix that may also include social media (Brusse et al. 2014; Hefler et al. 2019) as part of the overall communication strategy.

Carson et al.'s reviews (2014) of smoking cessation and tobacco prevention studies tailored for indigenous populations around the world have a particular focus on Aboriginal and Torres Strait Islander people in Australia. A list of factors involved in successful interventions can be drawn from the work of Carson et al. (2014), Ivers (2011, 2014), Martin et al. (2019) and Upton et al. (2014). Key among these factors are:

- multi-faceted interventions that observe various aspects of tobacco use at once, such as biochemical addiction, habit, cultural reasons for smoking, stressors, and psychological reasons for smoking

- interventions carried out among people who are already highly motivated to quit smoking, such as those with acute illnesses, who have family members with tobacco-related illnesses, or who want to quit for their children

- use of pharmacotherapy, particularly Champix (varenicline tartrate), Zyban (bupropion hydrochloride) and nicotine patches

- use of incentives (e.g. 'quit and win' competitions)

- programs that train health professionals in smoking cessation and motivational interviewing techniques

- behavioural support services that take account of cultural practices, traditions and language

- interventions involving health professionals in addition to community partnerships with community health organisations and culturally tailored campaigns

- training for the local healthcare workers in culturally sensitive interventions

Weston et al. (2009) and Couzos et al. (2015) have recommended approaches that combine community-owned policies with access to quit support services at the individual level, including access to behavioural and pharmacological therapies, provided by a local workforce trained in culturally sensitive interventions. Upton et al. (2014) state that when the local community has ownership, commitment to the policy is strengthened, enabling smoke-free policies to be more effectively implemented. They found this to be especially true in remote and rural settings, and more recently with high-intensity counselling and other brief interventions supplemented with nicotine replacement therapy (Davey et al. 2015; Lancaster $\&$ Stead 2017). Thus nicotine replacement should be a focus of necessarily longer-term, 
multi-faceted quit programs of higher intensity within these communities (Kuehn 2010; Carson et al. 2014).

Action of course requires quit programs that are well funded, resourced and managed and, above all, well evaluated, so that lessons can be learnt for future programs. As Tom Calma, in his role as Aboriginal and Torres Strait Islander Social Justice Commissioner and Race Discrimination Commissioner, pointedly stated in 2008,

It is not credible to suggest that one of the wealthiest nations in the world cannot solve a health crisis affecting less than 3 per cent of its citizens. Research suggests that addressing Aboriginal and Torres Strait Islander health inequality will involve no more than a 1 per cent per annum increase in total health expenditure in Australia over the next ten years. If this funding is committed, then the expenditure required is then likely to decline thereafter.

Sadly, Commissioner Professor Calma's calls appear not to have been met. A 2017 report by the Australian Institute of Health and Welfare, measuring longer timeframes concluded the gap was in fact widening: ... life expectancy at birth increased for both Indigenous males and females during the ... period ... 2001-2005 to 2011-2015 ... However, greater increases in life expectancy at birth occurred for non-Indigenous males and females, meaning that the gap in life expectancy between Indigenous and non-Indigenous Australians widened during the reference period (AIHW 2017, p. vii).

This review has emphasised the disparity in success rates of quit smoking campaigns between the general public and Indigenous people, especially those in rural and remote communities. It has underlined the normative approach in the literature, written from the perspective of health professionals, policy-makers and those with expertise in marketing and media communications. It has demonstrated the importance of culturally sensitive communication between health service providers and Aboriginal and Torres Strait Islanders and highlighted the paucity of Indigenous voices on the issue. Professor Calma has placed emphasis on this aspect of the health crisis which sets Indigenous people apart from the wider population. Professor Calma's focus on a small increase in health funding, is surely small price to pay for a projected decline in smoking and ill-health and early deaths attributed to smoking among Indigenous people, a topic of increasing urgency, that casts this important issue in the economic terms which underpins much of the rhetoric about issues of social justice in contemporary Australia.

\section{References}

Abrams, D.B., Graham, A.L., Levy, D.T., Mabry, P.L. \& Orleans, C.T. 2010, 'Boosting population quits through evidence-based cessation treatment and policy', American Journal of Preventive Medicine, vol. 38, suppl. 3, pp. S351-63. https://doi.org/10.1016/j.amepre.2009.12.011

Australian Bureau of Statistics (ABS) 2014, Australian Aboriginal and Torres Strait Islander Health Survey: updated results, 2012-13 - Australia, cat. no. 4727.0.55.066, Table 1.3: 
Selected characteristics - 2001 to 2012-13, proportion of persons by Indigenous status, ABS, Canberra.

Australian Bureau of Statistics (ABS) 2015, Smoking Prevalence Rates: National Health Survey: first results, 2014-15, cat. no. 4364.0.55.001, ABS, Canberra, http://www.health.gov.au/internet/publications/publishing.nsf/Content/tobacco-controltoc $\sim$ smoking-rates Accessed 29 October 2019.

Australian Bureau of Statistics (ABS) 2016, 4714.0 - National Aboriginal and Torres Strait Islander Social Survey, 2014-15, ABS, Canberra, http://www.abs.gov.au/ausstats/abs@.nsf/mf/4714.0 Accessed 29 October 2019.

Australian Bureau of Statistics (ABS) 2019, National Health Survey: first results, 2017-18, cat. no. 4364.0.55.001, ABS, Canberra, https://www.abs.gov.au/ausstats/abs@.nsf/mf/4364.0.55.001 Accessed 29 October 2019.

Australian Government Department of Health 2019, 'Tobacco plain packaging', https://www.health.gov.au/health-topics/smoking-and-tobacco/tobacco-control/tobaccoplain-packaging Accessed 29 October 2019.

Australian Health Ministers' Advisory Council (AHMAC) 2015, Aboriginal and Torres Strait Islander Health Performance Framework: 2014 report, AHMAC, Canberra. Accessed 23 August 2018, https://www.pmc.gov.au/sites/default/files/publications/Aboriginal_and_Torres_Strait Islander_HPF_2014\%20-\%20edited\%2016\%20June2015.pdf Accessed 29 October 2019.

Australian Institute of Health and Welfare (AIHW) 2017, Trends in Indigenous Mortality and Life Expectancy 2001-2015: Evidence from the Enhanced Mortality Database, Canberra. Indigenous Evaluation Strategy Productivity Commission Issues Paper 2019. Australian Government Productivity Commission, Canberra. https://www.pc.gov.au/inquiries/current/indigenous-evaluation/issues/indigenousevaluation-issues.pdf Accessed 24 October 2019.

Bardsley, P. \& Olekalns, N. 1999, 'The impact of anti-smoking policies on tobacco consumption in Australia', Health Promotion Journal of Australia, vol. 9, no. 3, pp. $202-5$.

Borland, R., Winstanley, M.H. \& Reading, D. 2009, 'Legislation to institutionalize resources for tobacco control: The 1987 Victorian Tobacco Act', Addiction, vol. 104, no. 10, pp. 1623-9. https://doi.org/10.1111/j.1360-0443.2009.02701.x

Briggs, V.L., Lindorff, K.J. \& Ivers, R.G. 2003, 'Aboriginal and Torres Strait Islander Australians and tobacco', Tobacco Control, vol. 12, suppl. 2, pp. 5-8. https://doi.org/10.1136/tc.12.suppl 2.ii5

Brusse, C., Gardner, K., McAullay, D. \& Dowden, M. 2014, 'Social media and mobile apps for health promotion in Australian indigenous populations: Scoping review', Journal of Medical Internet Research, vol. 16, no. 12, p. e280. https://doi.org/10.2196/jmir.3614

Bryant, J., Bonevski, B., Paul, C.-L., McElduff, P. \& Attia, J. 2011a, 'A systematic review and meta-analysis of the effectiveness of behavioural smoking cessation interventions in selected disadvantaged groups', Addiction, vol. 106, no. 9, pp. 1568-85. https://doi.org/10.1111/j.1360-0443.2011.03467.x

Bryant, J., Bonevski, B., Paul, C.-L., O’Brien, J. \& Oakes, W. 2011b, 'Developing cessation interventions for the social and community service setting: A qualitative study of barriers to quitting among disadvantaged Australian smokers', BMC Public Health, vol. 11, p. 493. https://doi.org/10.1186/1471-2458-11-493

Buttle, F. \& Maklan, S. 2015, Customer relationship management: concepts and technologies (3rd edn), Routledge, Taylor \& Francis, London. 
Calma, T. 2008, 'Opening remarks, National Indigenous Health Equality Summit', 18 March 2008, Canberra. Australian Human Rights and Equal Opportunity Commission, Sydney. Accessed 22 June 2019, https://www.humanrights.gov.au/news/speeches/opening-remarks-national-indigenoushealth-equality-summit-tom-calma

Calma, T. 2011, 'Tackling Indigenous smoking', Of Substance: The National Magazine on Alcohol, Tobacco and Other Drugs, vol. 9, no. 2, pp. 28-9. Accessed 23 August 2018, http://www.atoda.org.au/wp-content/uploads/ofsubstance 2011 7-min-min.pdf

Campbell, C. \& Scott, K. 2011, 'Retreat from Alma Ata? The WHO's report on Task Shifting to community health workers for AIDS care in poor countries, Global Public Health, vol. 6, p.125-138. https://doi.org/10.1080/17441690903334232

Cancer Council Victoria 2013, Smoking and disadvantage: evidence brief 2013, Australian National Preventive Health Agency, Canberra. Accessed 23 August 2018, http://www.health.gov.au/internet/publications/publishing.nsf/Content/smokingdisadvantage-evidence-brief

Carson, K.V., Jayasinghe, H., Smith, B., Newchurch, J., Brinn, M., Veale, A. et al. 2014, 'Smoking cessation and tobacco prevention in Indigenous populations', Evidence Base (Australia and New Zealand School of Government), vol. 3, pp. 1-51. https://www.exeley.com/evidence base/doi/10.21307/eb-2014-003

Centre for Excellence in Indigenous Tobacco Control (CEITC) 2008, Indigenous tobacco control in Australia: everybody's business. National Indigenous tobacco control research roundtable report, CEITC, University of Melbourne; 2008. Accessed 23 August 2018, http://www.ceitc.org.au/ceitc-publications-and-resources

Chamberlain, C., Perlen, S., Brennan, S., Rychetnik, L., Thomas, D., Maddox, R. et al. 2017, 'Evidence for a comprehensive approach to Aboriginal tobacco control to maintain the decline in smoking: an overview of reviews among Indigenous peoples', Systematic Reviews, vol. 6, p. 135. Accessed 29 October 2019. https://systematicreviewsjournal.biomedcentral.com/articles/10.1186/s13643-017-0520$\underline{9}$

Chapman, S. 1993, 'Unravelling gossamer with boxing gloves: problems in explaining the decline in smoking', BMJ, vol. 307, no. 6901, pp. 429-32. https://doi.org/10.1136/bmj.307.6901.429

Chapman, S., Borland, R., Scollo, M., Brownson, R.C., Dominello, A. \& Woodward, S. 1999, 'The impact of smoke-free workplaces on declining cigarette consumption in Australia and the United States', American Journal of Public Health, vol. 89, no. 7, pp. 1018-23. https://doi.org/10.2105/ajph.89.7.1018

Clifford, D., Hill, S. \& Collin, J. 2014, 'Seeking out “easy targets”? Tobacco companies, health inequalities and public policy’, Tobacco Control, vol. 23, pp. 479-83.

https://doi.org/10.1136/tobaccocontrol-2013-051050

Closing the Gap Report 2019, Accessed 25 October 2019. https://healthinfonet.ecu.edu.au/learn/health-system/closing-the-gap/

Couzos, S., Nicholson, A.K., Hunt, J.M., Davey, M.E., May, J.K., Bennet, P.T. et al. 2015, 'Talking about the smokes: a large-scale, community-based participatory research project', Medical Journal of Australia, vol. 202, suppl. 10, pp. S13-19. https://doi.org/10.5694/mja14.00875

Dalglish, E., McLaughlin, D., Dobson, A. \& Gartner, C. 2013, 'Cigarette availability and price in low and high socioeconomic areas', Australian and New Zealand Journal of Public Health, vol. 37, pp. 371-6. https://doi.org/10.1111/1753-6405.12086

Davey, M.E., Hunt, J.M., Foster, R., Couzos, S., van der Sterren, A.E., Sarin, J. et al. 2015, 'Tobacco control policies and activities in Aboriginal community-controlled health 
services', Medical Journal of Australia, vol. 202, suppl. 10. pp. S63-6. https://doi.org/10.5694/mja15.00200

Demaio, A., Drysdale, M. \& de Courten, M. 2012, 'Appropriate health promotion for Australian Aboriginal and Torres Strait Islander communities: crucial for closing the gap', Global Health Promotion, vol. 19, no. 2, pp. 58-62.

https://doi.org/10.1177/1757975912441230

DiGiacomo, M., Davidson, P.M., Abbott, P.A., Davison, J., Moore, L. \& Thompson, S.C. 2011, 'Smoking cessation in indigenous populations of Australia, New Zealand, Canada, and the United States: elements of effective interventions', International Journal of Environmental Research and Public Health, vol. 8, no. 2, pp. 388-410. https://doi.org/10.3390/ijerph8020388

Dingle, S. 2014, 'Cuts to Indigenous anti-smoking programs will contribute to early deaths of smokers: Tom Calma', The World Today, 8 July. Accessed 29 October 2019. http://www.abc.net.au/worldtoday/content/2014/s4041473.htm

Downing, R. \& Kowal, E. 2011, 'Putting Indigenous cultural training into nursing practice', Contemporary Nurse, vol. 37, no. 1, pp. 10-20.

https://doi.org/10.5172/conu.2011.37.1.010

Eades, S.J., Sanson-Fisher, R.W., Wenitong, M., Panaretto, K., D’Este, C., Gilligan, C. et al. 2012, 'An intensive smoking intervention for pregnant Aboriginal and Torres Strait Islander women: a randomised controlled trial', Medical Journal of Australia, vol. 197, no. 1, pp. 42-6. https://doi.org/10.5694/mja12.11221

Fredericks, B. 2006, 'Which way? Educating for nursing Aboriginal and Torres Strait Islander peoples', Contemporary Nurse, vol. 23, pp. 87-99. https://doi.org/10.5172/conu.2006.23.1.87

Gould, G.S., Bittoun, R. \& Clarke, M.J. 2015, ‘A pragmatic guide for smoking cessation counselling and the initiation of nicotine replacement therapy for pregnant Aboriginal and Torres Strait Islander smokers', Journal of Smoking Cessation, vol. 10, pp. 96-105. https://doi.org/10.1017/jsc.2014.3

Gould, G.S., McEwen, A., Watters, T., Clough, A.R. \& van der Zwan, R. 2013, 'Should antitobacco media messages be culturally targeted for Indigenous populations? A systematic review and narrative synthesis', Tobacco Control, vol. 22, no. 4, p. e7. https://doi.org/10.1136/tobaccocontrol-2012-050436

Gould, G.S., Watt, K., McEwen, A., Cadet-James, Y. \& Clough, A.R. 2015, 'Predictors of intentions to quit smoking in Aboriginal tobacco smokers of reproductive age in regional New South Wales (NSW), Australia: quantitative and qualitative findings of a cross-sectional survey', BMJ Open, vol. 5, p. e007020 https://doi.org/10.1136/bmjopen2014-007020

Gould, G.S., Watt, K., West, R., Cadet-James, Y. \& Clough, A.R. 2016, 'Can smoking initiation contexts predict how adult Aboriginal smokers assess their smoking risks? A cross-sectional study using the "Smoking Risk Assessment Target"', BMJ Open, vol. 6, p. e010722. https://doi.org/10.1136/bmjopen-2015-010722

Greenhalgh, E.M., Bayly, M. \& Winstanley, M.H. 2019, '1.3 Prevalence of smoking adults', in M.M. Scollo \& M.H. Winstanley (eds), Tobacco in Australia: facts and issues, Cancer Council Victoria, Melbourne. Accessed 209 October 2019. http://www.tobaccoinaustralia.org.au/chapter-1-prevalence/1-3-prevalence-of-smokingadults

Hefler, M., Kerrigan, V., Freeman, B., Boot, G.R. \& Thomas, D.P. 2019, 'Using Facebook to reduce smoking among Australian Aboriginal and Torres Strait Islander people: a participatory grounded action study', BMC Public Health, vol. 19, p. 615. https://doi.org/10.1186/s12889-019-6918-7 
Hill, K., Barker, B. \& Vos, T. 2007, 'Excess indigenous mortality: Are Indigenous Australians more severely disadvantaged than other Indigenous populations?', International Journal of Epidemiology, vol. 36, pp. 580-9. https://doi.org/10.1093/ije/dym011

Hirono, K.T. \& Smith, K.E. 2016, 'Australia's $\$ 40$ per pack cigarette tax plans: the need to consider equity', Tobacco Control, vol. 25, no. 2, pp. 141-6. https://doi.org/10.1136/tobaccocontrol-2016-053608

Hoek, J. \& Smith, K. 2016, 'A qualitative analysis of low income smokers' responses to tobacco excise tax increases', International Journal of Drug Policy, vol. 37, pp. 82-9. https://doi.org/10.1016/i.drugpo.2016.08.010

Holland, C. 2018, A Ten-Year Review: The Closing the Gap strategy and recommendations for reset. Close the Gap Campaign Steering Committee for Indigenous Health Equality. Accessed 10 September 2018, https://nationalcongress.com.au/wpcontent/uploads/2018/02/CTG-2018_FINAL_WEB-8th-Feb-2018.pdf

Hudson, S. 2017, Evaluating Indigenous programs: a toolkit for change. Research report. Centre for Independent Studies, Sydney. Accessed 22 June 2019, https://www.pc.gov.au/_data/assets/pdf_file/0005/219731/subdr544-human-servicesreform-attachment2.pdf

Hudson, S. 2016, Mapping the Indigenous Program and Funding Maze. Research report. Centre for Independent Studies, Sydney. Accessed 22 June 2019, https://www.cis.org.au/publications/research-reports/mapping-the-indigenous-programand-funding-maze/

Ivers, R. 2001, Indigenous Australians and tobacco - a literature review, Menzies School of Health Research and the Co-operative Research Centre for Aboriginal and Tropical Health, Darwin. Accessed 23 August 2018, https://www.lowitja.org.au/sites/default/files/docs/Indigenous Australians and Tobacc o.pdf

Ivers, R. 2014, Attachment two: the NSW strategic framework for Aboriginal tobacco resistance and control - supporting evidence. Aboriginal Health \& Medical Research Council of NSW and NSW Ministry of Health, Sydney.

Ivers, R.G. 2011, Anti-tobacco programs for Aboriginal and Torres Strait Islander people 2011, Resource sheet no. 4 produced for the Closing the Gap Clearinghouse, Cat. no. IHW 37, Australian Institute of Health and Welfare, Canberra, and Australian Institute of Family Studies, Melbourne. Accessed 23 August 2018, https://www.aihw.gov.au/reports/indigenous-australians/anti-tobacco-programs-foraboriginal-and-torres-st/contents/table-of-contents

Ivers, R.G., Castro, A., Parfitt, D., Bailie, R.S., D’Abbs, P.H. \& Richmond, R.L. 2006, 'Evaluation of a multi-component community tobacco intervention in three remote Australian Aboriginal communities', Australian and New Zealand Journal of Public Health, vol. 30, no. 2, pp. 132-6. https://doi.org/10.1111/j.1467-842x.2006.tb00105.x

Johnson, V. \& Thomas, D.P. 2010, 'What works in Indigenous tobacco control? The perceptions of remote Indigenous community members and health staff', Health Promotion Journal of Australia, vol. 21, no. 1, pp. 45-50. https://doi.org/10.1071/he10045

Johnston, V., Westphal, D.W., Glover, M., Thomas, D.P., Segan, C. \& Walker, N. 2013, 'Reducing smoking among indigenous populations: new evidence from a review of trials', Nicotine and Tobacco Research, vol. 5, pp. 1329-38. https://doi.org/10.1093/ntr/ntt022 
King, R. \& Brown, A. 2015, Next steps for Aboriginal Health research: exploring how research can improve the health and wellbeing of Aboriginal people in South Australia. Aboriginal Health Council of South Australia, Adelaide.

Kuehn, B. 2010, 'FDA considering data on long-term use of nicotine replacement therapy products', JAMA, vol. 304, p. 2580. https://doi.org/10.1001/jama.2010.1804

Lancaster, T. \& Stead, L.F. 2017, 'Individual behavioural counselling for smoking cessation', Cochrane Database of Systematic Reviews. Accessed 22 June 2019, https://www.cochranelibrary.com/cdsr/doi/10.1002/14651858.CD001292.pub3/full

Marley, J.V., Atkinson, D., Kitaura, T., Nelson, C., Gray, D., Metcalf, S. et al. 2014, 'The Be Our Ally Beat Smoking (BOABS) study, a randomised controlled trial of an intensive smoking cessation intervention in a remote aboriginal Australian health care setting', BMC Public Health, vol. 14, p. 32. https://doi.org/10.1186/1471-2458-14-32

Martin, K., Dono, J., Stewart, H. (Bundamurra), Sparrow, A., Miller, C., Roder, D. \& Bowden, J. 2019, 'Evaluation of an intervention to train health professionals working with Aboriginal and Torres Strait Islander people to provide smoking cessation advice', Australian and New Zealand Journal of Public Health, vol. 43, no. 2, pp. 156-62. https://doi.org/10.1111/1753-6405.12879

Miller, C.L., Wakefield, M. \& Roberts L. 2003, 'Uptake and effectiveness of the Australian telephone Quitline service in the context of a mass media campaign', Tobacco Control, vol. 12, suppl. 2, pp. 53-8. https://doi.org/10.1136/tc.12.suppl_2.ii53

Minichiello, A., Lefkowitz, A.R., Firestone, M., Smylie, J.K. \& Schwartz, R. 2016, 'Effective strategies to reduce commercial tobacco use in Indigenous communities globally: a systematic review', BMC Public Health, vol. 16, p. 21. https://doi.org/10.1186/s12889015-2645-X

Muir, S. \& Dean, M. 2017, 'Evaluating the outcomes of programs for Indigenous families and communities, CFCA Practice Resource, February, https://aifs.gov.au/cfca/publications/ evaluating-outcomes-programs-indigenousfamilies-and-communities' (accessed 23 October 2019).

Myers, P. \& Vickers, N. 2015, National Tobacco Campaign Research Evaluation: final report. Social Research Centre, Australian National University, Canberra, for the Australian Government Department of Health. Accessed 23 August 2018, http://www.quitnow.gov.au/internet/quitnow/publishing.nsf/Content/2B624C441CC88 083CA257E530081C8AD/\$File/2015\%20NTC\%20Report.pdf

National Preventative Health Taskforce 2008, Australia: the healthiest country by 2020: a discussion paper, National Preventative Health Taskforce, Canberra.

O'Brien, J., Geikie, A., Jardine, A., Oakes, W. \& Salmon, A. 2010, 'Integrating smoking care in community welfare agencies to reach disadvantaged people: findings from the Smoking Matters project', Health Promotion Journal of Australia, vol. 21, pp. 176-82. https://doi.org/10.1071/he10176

Power, J., Grealy, C. \& Rintoul, D. 2009, 'Tobacco interventions for Indigenous Australians: a review of current evidence', Health Promotion Journal of Australia, vol. 20, pp. 18694. https://doi.org/10.1071/he09186

Raven, M., Katz, I., Newton, B.J. \& Bates, S. 2016, OCHRE Evaluation Plan (Overview and Stage 1). Social Policy Research Centre, UNSW Australia, Sydney.

Robertson, J., Stevenson, L., Usher, K., Devine, S. \& Clough, A. 2015, 'A review of trends in Indigenous Australian tobacco research (from 2004 to 2013), its associated outputs and evidence of research translation', Nicotine and Tobacco Research, vol. 17, no. 8, pp. 1039-48.

Stead, L.F., Hartmann-Boyce, J., Perera, R. \& Lancaster, T. 2013, 'Telephone counselling for smoking cessation', Cochrane Database of Systematic Reviews. Accessed 10 
September 2018, https://www.cochranelibrary.com/cdsr/doi/10.1002/14651858.CD002850.pub3/full

Steering Committee for the Review of Government Service Provision 2009, National Agreement Performance Information 2008-09: National healthcare agreement, p. 19, Productivity Commission, Melbourne.

Tane, M.P., Hefler, M. \& Thomas, D.P. 2018, 'An evaluation of the "Yaka Darali"' Tackling Indigenous Smoking program in East Arnhem Land: Yolnu people and their connection to yarali", Health Promotion Journal of Australia, vol. 29, pp. 10-17. https://doi.org/10.1002/hpja.1

Thomas, D.P., Davey, M. E., Briggs V. L., \& Borland, R. 2015, 'Talking About The Smokes: summary and key findings', Medical Journal of Australia, vol 202, no.10, S3-S4. https://doi.org/10.5694/mja15.00464

Thomas, D.P., Johnston, V. \& Fitz, J. 2010, 'Lessons for Aboriginal tobacco control in remote communities: An evaluation of the Northern Territory "tobacco project", Australian and New Zealand Journal of Public Health, vol. 34, no. 1, pp. 34-45. https://doi.org/10.1111/j.1753-6405.2010.00472.x

Thomas, D.P., Ferguson, M., Johnston, V. \& Brimblecombe, J. 2013, 'Impact and perceptions of tobacco tax increase in remote Australian Aboriginal communities', Nicotine and Tobacco Research, vol. 15, no. 6. pp. 1099-1106. https://doi.org/10.1093/ntr/nts232

Tobacco Advertising Prohibition Act 1992 as amended 2016, Accessed 14 September 2018, https://www.legislation.gov.au/Details/C2016C00899

Tobacco and Other Smoking Products Act 1998 (Q1d) as amended. Accessed 12 September 2018, https://www.legislation.qld.gov.au/view/pdf/2018-01-01/act-1998-001

Upson, D. 2015, 'Social determinants of cigarette smoking' in Loddenkemper, R. and Kreuter, M. (eds), The Tobacco Epidemic (2nd edn), ch. 16, Karger, Basel.

Upton, P., Davey, R., Evans, M., Mikhailovich, K., Simpson, L. \& Hacklin, D. 2014, Tackling Indigenous Smoking and Healthy Lifestyle Programme Review: a rapid review of the literature. Centre for Research and Action in Public Health, University of Canberra. Accessed 23 August 2018, https://www.health.gov.au/internet/main/publishing.nsf/Content/904B8752C99678A1C A257EA00026976F/\$File/TIS-and-Healthy-Lifestyle-Programme-Review A-RapidReview-of-the-Literature.pdf

Van der Sterren, A., Greenhalgh, E.M., Knoche, D. \& Winstanley, M.H. 2016, 'Tobacco action initiatives targeting Aboriginal peoples and Torres Straits Islanders', in Scollo, M.M. \& Winstanley, M.H. (eds), Tobacco in Australia: Facts and issues, ch. 8.10, Cancer Council Victoria, Melbourne. Accessed 23 August 2018, http://www.tobaccoinaustralia.org.au/chapter-8-aptsi/8-10-interventions-targetingaboriginal-peoples-an

Vos, T., Barker, B., Stanley, L. \& Lopez, A. 2007, The burden of disease and injury in Aboriginal and Torres Strait Islander peoples 2003 (No. 978186499889 4), University of Queensland, Brisbane.

Wakefield, M.A., Durkin, S., Spittal, M.J., Siahpush, M., Scollo, M., Simpson, J.A., et al. 2008, 'Impact of tobacco control policies and mass media campaigns on monthly adult smoking prevalence', American Journal of Public Health, vol. 98, no. 8, pp. 1443-50. https://doi.org/10.2105/ajph.2007.128991

Wakefield, M.A., Loken, B. \& Hornik, R.C. 2010, 'Use of mass media campaigns to change health behaviour', Lancet, vol. 376, no. 9748, pp. 1261-71. 
Walsh, R.A., Tzelepis, F. \& McKenzie, J. 2002,'Environmental tobacco smoke in homes, motor vehicles and licensed premises: community attitudes and practices', Australian and New Zealand Journal of Public Health, vol. 26, no. 6, pp. 536-42. https://doi.org/10.1111/j.1467-842x.2002.tb00363.x

Weston, R., Brooks, R., Gladman, J., Senior, K., Denley, L., Silove, D. et al. 2009, 'Ethical research in partnership with an Indigenous community', Australasian Psychiatry, vol. 17, suppl. 1, pp. S51-3. https://doi.org/10.1080/10398560902948738

World Health Organisation Report. 2010, A Conceptual Framework for Action on the Social Determinants of Health, World Health Organization Geneva 2010. Accessed October 23, 2019. https://www.who.int/social_determinants/corner/SDHDP2.pdf

Wright, C.J.C., Schwarzman, J., Dietze, P.M., Crockett, B. \& Lim, M.S.C. 2019, 'Barriers and opportunities in the translation of mobile phone and social media interventions between research and health promotion practice in Australia: a qualitative study of expert perspectives', Health Research Policy and Systems, vol. 17, no. 1, p. 5. https://doi.org/10.1186/s12961-018-0406-X 